\title{
Abkürzungen.
}

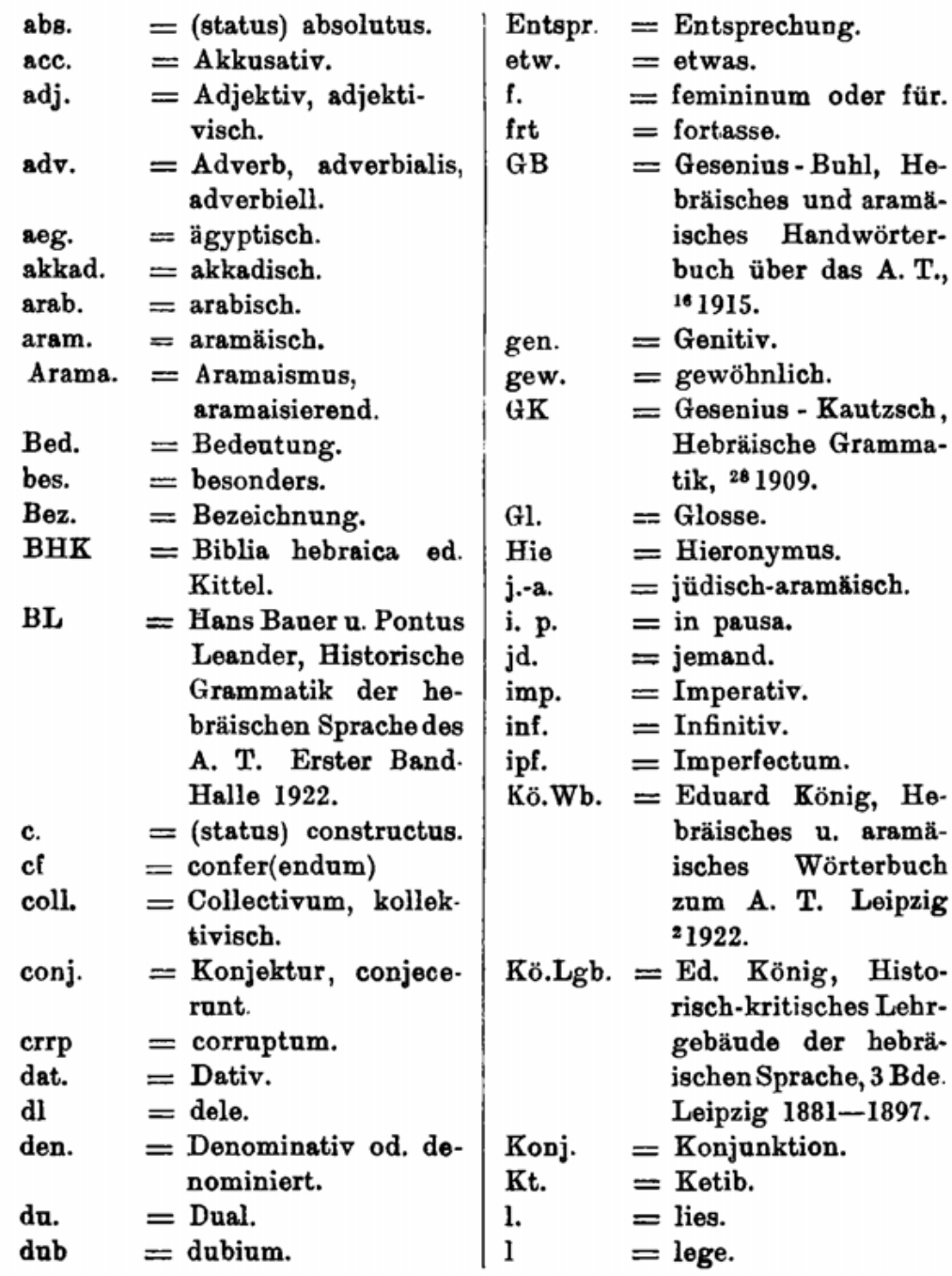


$1 \mathrm{c}=$ lege cum.

m. = masculinum od. mit.

mch. = machen.

mlt $=$ multi(s) etc.

MSS $=$ codices manu scripti.

nh. = neuhebräisch.

nonn = nonnulli(s) etc.

od. = oder.

ö. = öfter.

P. $\quad=$ Person.

pf. = Perfectum.

pl. = Plural.

poet. = poetisch.

pr $=$ pro.

praep. = Präposition.

prb = probabiliter.

prps = propositum.

pt. $\quad=$ Partizipium.

Qr. $\quad=$ Qere.

s. $\quad=$ sein oder siehe.

S. $=$ Sache.

Schr. = Schreibfehler.

sg. = Singular.

sp(ez). = speziell.

st. $=(\mathrm{an})$ statt.

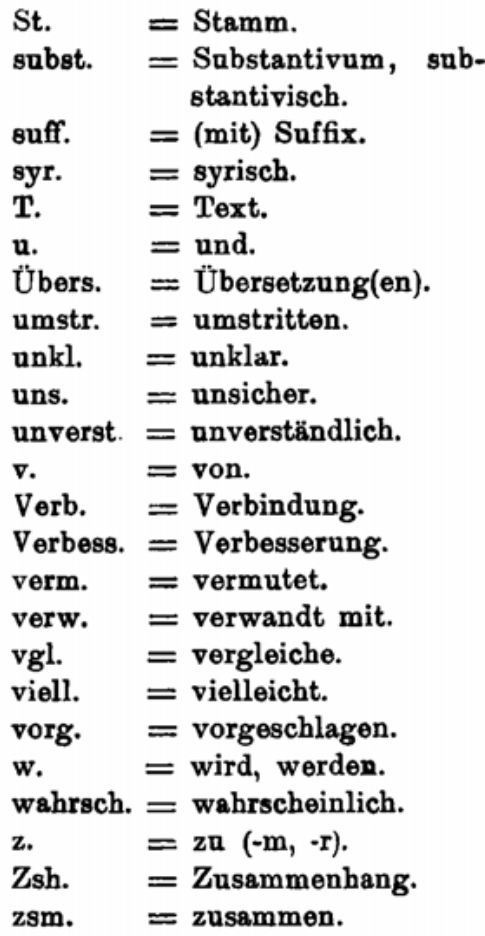

suff. $=$ (mit) Suffix.

syr. = syrisch.

T. = Text.

u. $\quad=$ und.

Übers. = Übersetzung(en).

umstr. = umstritten.

unkl. = unklar.

uns. = unsicher.

unverst. = unverständlich.

v. = von.

Verb. = Verbindung.

Verbess. = Verbesserung.

verm. = vermutet.

verw. = verwandt mit.

vgl. = vergleiche.

viell. $=$ vielleicht.

vorg. = vorgeschlagen

w. = wird, werden.

wahrsch. $=$ wahrscheinlich.

z. $\quad=z \mathbf{n}(-\mathrm{m},-\mathrm{r})$.

zsm. = zusammen.

* = die Form ist im mass. Text nicht belegbar.

$t=$ Bedentung ist unsicher.

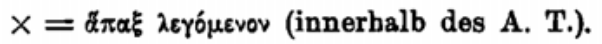

$\mathrm{O}=$ bildlich für...

$\|=$ paralleler Ausdrack zu ..., steht parallel zu ...

$\sim=$ vertritt das jeweilige durch ] abgeschlossene Stichwort in der dem Stichwort folgenden Ausführung.

$Q$ Ni. Pi. Pu. Hi. Ho. Hp.

Für die Textkritik sind die im textkritischen Apparat der Biblia Hebraica edidit Rud. Kittel, Editio tertia denuo elaborata (Liber Psalmorum. Praeparavit F. Buhl. Stuttgartiae 1930) benutzten Abkürzungen als bekannt vorausgesetzt und verwertet. 


\section{Zur Beachtung:}

1. Nicht verzeichnet sind, da als allgemein bekannt vorauszusetzen: die Zahlwörter, die Pronomina und einige häufig vorkommende

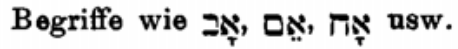

2. a-Imperfekte (ausgenommen die Verba laryngalia) sind durch ${ }_{n} \mathrm{a}^{\mu}$ lin $\mathrm{kg}$ vom Stichwort kenntlich gemacht.

3. Die Grundbedeutung des Verbums, bzw. die Bedeutung des Qal, ist ohne besonderen Hinweis aufgeführt.

4. Das Geschlecht des Nomens bleibt in der Regel unbezeichnett. Dort, wo $\pi_{\tau}$ die Endung ist, hat der Leser ein femin. vorauszusetzen; dort, wo keine Endung vorhanden ist, ein mascul. In den übrigen Fällen ist das Geschlecht ausdrücklich angegeben und zwar durch ${ }_{n}$ f." bzw. "m." lin ks vom Stichwort.

5. Die Eigennamen sind in besonderem Verzeichnis am SchluB aufgeführt.

Von wichtigster neuer deutscher Literatur seit 1923 sei genannt:

A. Bertholet, Die Psalmen. 1923. = Die Hl. Schrift, des A. T. . übersetzt von E. Kautzsch t. 4. Aufl. herausgegeben von A. Bertholet, 2. Bd., S. 113-275.

Fr. Wutz, Die Psalmen textkritisch untersucht. 1925.

H. Gunkel, Die Psalmen übersetzt u. erklärt. 1926.

Ed. König, Die Psalmen eingeleitet, übersetzt u. erklärt. 1927.

N. Peters, Das Buch der Psalmen. 1930.

F. Buhl, Liber Psalmorum. Editio tertia denuo elaborata $1930=$ BHK 11 .

H. Schmidt, Die Psalmen. 1934.

A. Weiser, Die Psalmen ausgewăhlt, übersetzt und erklärt. 1935.

H. Herkenne, Das Buch der Psalmen übersetzt u. erklärt. 1936.

S. Mowinckel, Psalmenstudien. IV. Die technischen Termini der Psalmenüberschriften. 1923. V. Segen und Fluch in Israels Kult und Psalmendichtung. 1924. VI. Die Psalmendichter. 1924.

G. Quell, Das kultische Problem der Psalmen. 1926.

H. Schmidt, Das Gebet der Angeklagten im A. T. 1928.

H. Gunkel, Einleitung in die Psalmen. Zu Ende geführt von J. Begrich. 1933.

Für weitere Literatur siehe M. Haller, Ein Jahrzehnt Psalmenforschung $=$ Theol. Rundschau, Neue Folge, 1929, 8. 377-402. 
